\title{
Modelling short-term tension stiffening in tension members
}

\author{
R. L. Vollum, N. Afshar and B. A. Izzuddin
}

Imperial College London

Recent research has questioned the validity of bond-slip relationships owing to the 'necessity for the concrete to be able to slip past the ribs on the bar'. Conversely, it is suggested in this paper that bond-slip models are simply a numerical device that relates bond stress to the relative displacements between the concrete, which surrounds the internal cracking zone, and steel. This paper shows that the short-term response of a reinforced concrete tension member with a central reinforcement bar is predicted well by a one-dimensional non-linear finite-element analysis incorporating a trilinear idealisation of the Model Code 1990 bond-slip relationship. The authors' analysis is significant since it is shown to predict many of the trends in behaviour observed in tests associated with tension stiffening and cracking. Different approaches are adopted in Eurocode 2 (EC2) (2004) for modelling tension stiffening in the calculation of crack width and mean axial extension. These approaches are reviewed in the light of the authors' finite-element analysis and existing experimental data. The EC2 models for mean axial strain are shown to be reasonable but the crack spacing formula overestimates crack spacing in the tension members considered in this study.

\section{Introduction}

The tensile response of cracked reinforced concrete members depends on the interaction between the reinforcement and surrounding concrete. An incompatibility in strain arises between the reinforcement and concrete after cracking. The difference in extension between the reinforcement and concrete between cracks is conventionally thought to be accommodated by slip between the reinforcement and concrete. In a one-dimensional analysis, the crack width is equal to the sum of the slips to either side of the crack.

The present paper reviews the validity of the $\mathrm{MC}^{1} 0^{1}$ bond-slip relationship in light of Beeby and Scott's ${ }^{2-4}$ experimental data from tension specimens with internally strain gauged bars. Beeby and $\mathrm{Scott}^{2-4}$ questioned the validity of bond-slip relationships owing to the "necessity for the concrete to be able to slip past the ribs on the bar'. They went on to suggest that the incompatibility between the strains in

Department of Civil and Environmental Engineering, Imperial College London, South Kensington Campus, London SW7 2AZ, UK

(MACR-D-07-00125) received 12 October 2007; accepted 27 December 2007 the concrete and reinforcement is accommodated by internal cracking in the concrete around the bar of the type first observed by Goto. ${ }^{5}$ Beeby and Scott proposed an elastic model for the concrete bar interaction, incorporating springs of varying stiffness chosen to develop a uniform distribution of bond stress along the reinforcement. While theoretically valid, the current authors believe that Beeby and Scott's ${ }^{2-4}$ fundamental objection to bond-slip models is irrelevant in the context of numerical models for bond-slip which relate bond stress to the relative displacements between the concrete, which surrounds the internal cracking zone, and steel.

More significantly, Beeby and $\mathrm{Scott}^{2-4}$ questioned the use of bond-slip models since they found that bond stresses were almost constant between cracks, initially increasing with load, before reaching a constant value. The conclusion that bond stress is uniform between cracks, and increases with load, would seem to invalidate the use of the MC90 bond-slip relationship, which assumes that bond stress increases with slip. The current authors therefore re-examined Beeby and Scott's ${ }^{2}$ Durham strain data to determine whether the bond stress was uniformly distributed between cracks, as reported by Beeby and $\mathrm{Scott}^{2-4}$ or increased with slip as usually assumed. 


\section{Analysis of bond-slip relationship in Durham tension tests}

Beeby and $\mathrm{Scott}^{2}$ carried out a series of tension tests at the University of Durham on specimens $1200 \mathrm{~mm}$ long by $120 \mathrm{~mm}$ square which were reinforced with a central reinforcement bar that varied in diameter between 12 and $20 \mathrm{~mm}$. The reinforcement bars were internally strain gauged with gauges at $15 \mathrm{~mm}$ centres. The Durham ${ }^{2}$ specimens T12B1, T16B1, T16B2 and T20B1 were considered in the present work. The current authors reanalysed the Durham ${ }^{2}$ reinforcement strain data to determine the relationship between bond stress and slip. The strain in the reinforcement varied between a minimum approximately mid-way between cracks, at the point of zero slip, to a maximum at cracks where the slip is greatest. Mean strains were calculated in the concrete at each strain gauge from the mean stress in the concrete, which was derived from axial equilibrium. The slip was calculated by subtracting the extension of the concrete from that of the reinforcement with all extensions measured from the point of zero slip. The mean extension of the concrete was estimated by numerically integrating the strains in the concrete. Bond stresses were calculated adjacent to cracks and over the development length at each end of the specimens. Local bond stresses were initially calculated from the difference between the strains measured at adjacent gauges, which were positioned at $15 \mathrm{~mm}$ centres. The analysis showed that the relationship between bond stress and slip varied significantly along the length of each tension member and locally between adjacent strain gauges. The following two approaches were used to develop a smooth bond-slip relationship of the form used in $\mathrm{MC} 90^{1}$ which can be expressed as

$$
\tau=\tau_{\max }\left(s / s_{1}\right)^{\alpha}
$$

where $s$ denotes slip. In MC90, $\tau_{\max }$ is taken as $2 \sqrt{ } f_{\mathrm{c}}, s_{1}$ as $0.6 \mathrm{~mm}$ and $\alpha$ as 0.4 for the conditions appropriate to the Durham tension tests.

(a) Bond stresses were estimated from the slope of a line of best fit, constructed with the method of least squares, through a graph of $\Delta T /(\pi \phi \Delta)$ (where $\Delta T$ is the increment in tensile force in the reinforcement from the adjacent point of zero slip and $\phi$ is the bar diameter) plotted against the distance $x$ along the bar from the point of zero slip (see Fig. $1)$. The line of best fit was assumed to be a power law of the form $\Delta T /(\pi \phi \Delta)=a x^{\mathrm{b}}$, which was typically found to give at least as good a correlation with the test data as a linear relationship which corresponds to a uniform bond stress.

(b) The method of least squares (see Fig. 2) was used to construct a line of best fit through a plot of the local bond stress between strain gauges plotted against slip. The line of best fit was assumed to have the same form as equation (1).

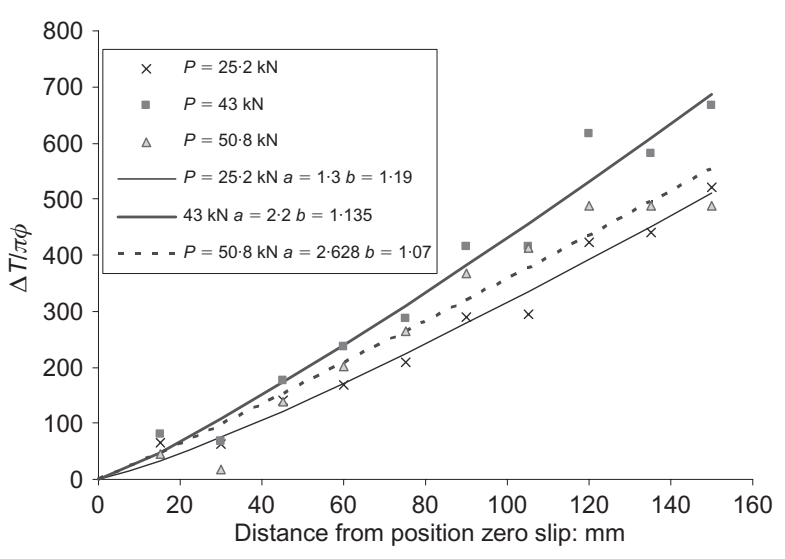

Fig. 1. Derivation of bond stress in T12B1 with method 1 between $x=880$ and $1030 \mathrm{~mm}$ (where $x$ is defined in the Durham data files ${ }^{2}$ )

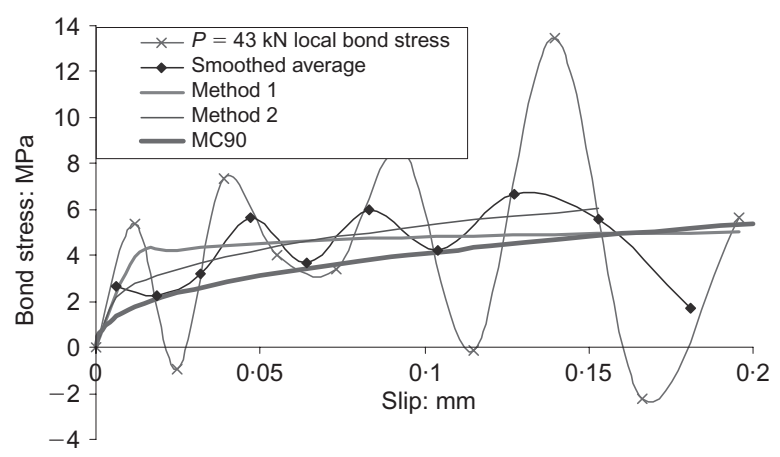

Fig. 2. Comparison of measured and calculated bond stresses in T12B1 between $x=880$ and $1030 \mathrm{~mm}$ at $P=43 \mathrm{kN}$

Typical results from the analyses are given in Figs 2 to 5 , in which the mean bond stress between adjacent strain gauges (smoothed average) is also plotted. The graphs support the hypothesis that bond stress increases between the point of zero slip and the adjacent crack, as implied by the $\mathrm{MC} 90^{1}$ bond-slip relationship. The peak bond stress tended to reduce significantly adjacent to cracks, particularly at higher slips, as shown in Fig. 2 , suggesting bond failure. The second procedure tended to give the most reliable estimate of the average bond stress between the point of zero slip and the adjacent cracks if points adjacent to cracks where bond failure occurred were excluded. Figs 3 and 5 show typical bond-slip relationships derived with method 2 for specimens $\mathrm{T} 12 \mathrm{~B} 1$ and $\mathrm{T} 16 \mathrm{~B} 1$ respectively. The figures also show the $\mathrm{MC}^{1} 0^{1}$ bond-slip relationship for comparison. Analysis showed that the bond-slip relationships derived using methods 1 and 2 varied both spatially along the member and with load as shown in Figs 3 and 5.

The data were therefore re-examined to determine whether the mean bond stress between cracks along the length of the member increased with applied load as implied by the $\mathrm{MC}^{1} 0^{1}$ bond-slip relationship. To this end, mean bond stresses were calculated in specimens 


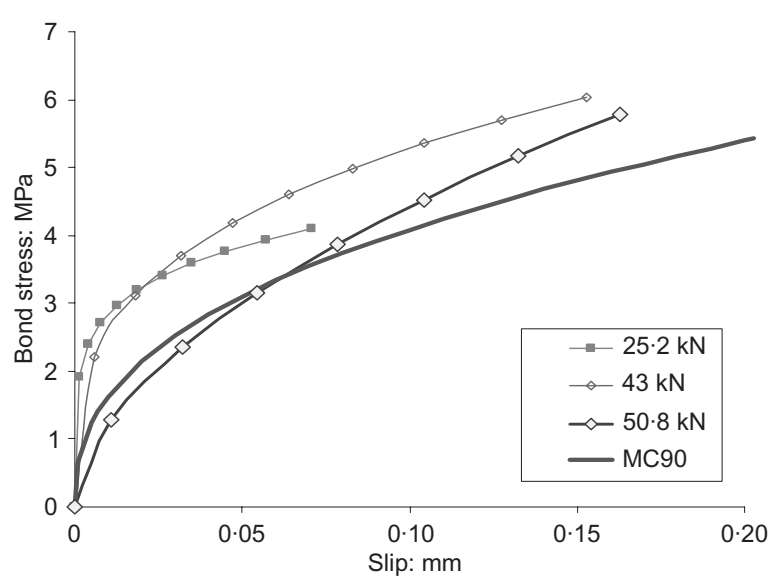

Fig. 3. Comparison between bond-slip relationships in T12B1 derived with MC90 and method 2 between $x=880$ and $1030 \mathrm{~mm}$

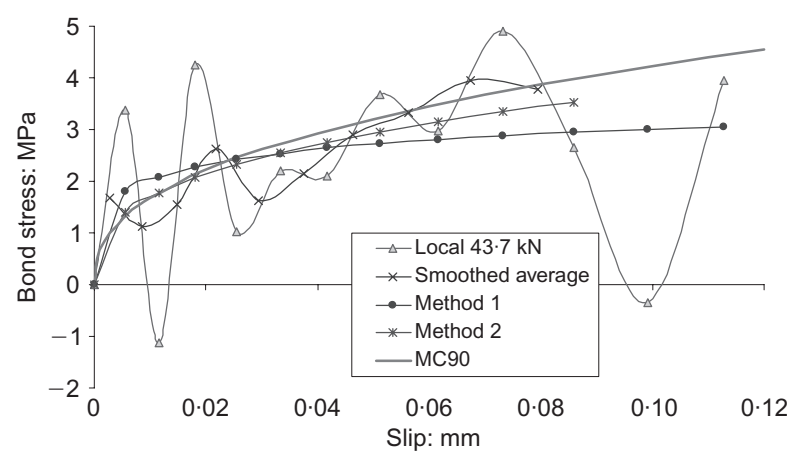

Fig. 4. Comparison of measured and calculated bond stresses in $T 16 B 1$ between $x=1090$ and $1240 \mathrm{~mm}$ at $P=43.7 \mathrm{kN}$

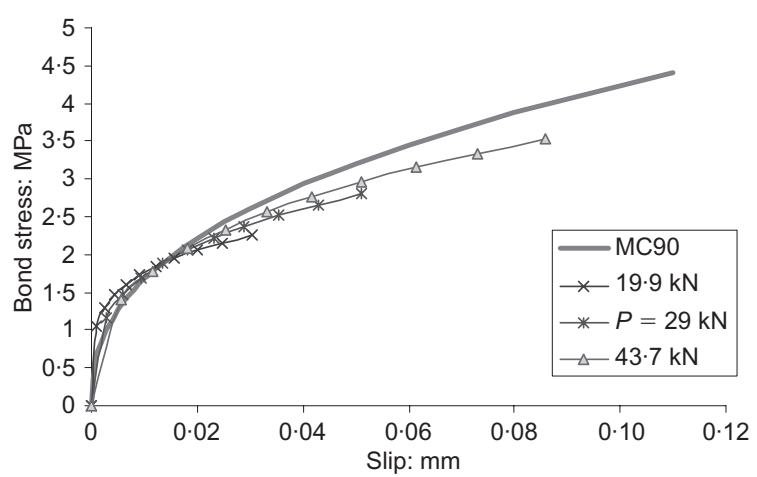

Fig. 5. Comparison between bond-slip relationships in T16B1 derived with MC90 and method 2 between $x=1240$ and $1420 \mathrm{~mm}$

T12B1, T16B1 and T20B1, at each loading stage, between cracks and adjacent points of zero slip. The slip was estimated to either side of each crack by subtracting the extension of the concrete from that of the reinforcement. The resulting bond stresses and slips were averaged at each load stage. The corresponding bond-slip relationships are plotted for members T12B1, T16B1 and T20B1 in Fig. 6. Bond stresses

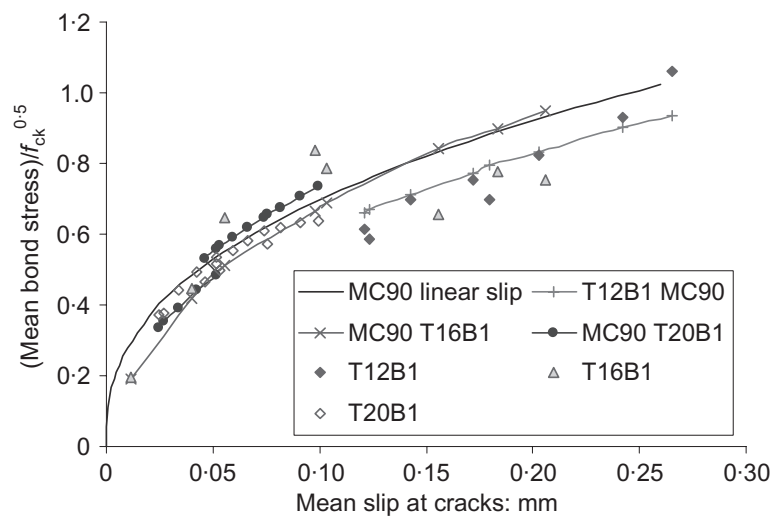

Fig. 6. Relationship between mean bond stress along member and slip

were also calculated with MC90 in each specimen at each strain gauge from the slips derived from the measured reinforcement strains at each load increment. The mean of the resulting bond stresses are plotted in Fig. 6 for each specimen. Analysis of the test data showed that the distribution of slip along the reinforcement bars between cracks was almost linear. This is reflected in Fig. 6, which also shows the mean bond stress given by MC90 for a linear distribution of slip. Fig. 6 shows that the measured and predicted mean bond stresses compare very favourably, suggesting that the $\mathrm{MC} 90^{1}$ bondslip relationship may be used to predict the response of the test specimens in one-dimensional non-linear finiteelement analysis (NLFEA). This conclusion is largely confirmed by the NLFEA described in the next section.

\section{NLFEA analysis}

A one-dimensional NLFEA analysis was carried out to investigate how realistically the response of tension members could be predicted with an analysis incorporating the $\mathrm{MC} 90^{1}$ bond-slip relationship. A one-dimensional analysis is consistent with the current authors' derivation of bond-slip relationships in the previous section but simplistic in the sense that plane sections are assumed to remain plane. In reality, cracks are widest at the surface of the concrete and narrowest at the surface of the reinforcement. A numerical, rather than analytical, approach was used in the bond-slip analysis since analytical solutions of the type presented by Balzas $^{6}$ are only valid at first cracking when the strains are equal in the reinforcement and concrete remote from a crack. Fig. 7 shows the one-dimensional finite-element mesh used to model the Durham ${ }^{2}$ tension members, employing the NLFEA analysis program ADAPTIC. $^{7}$ The reinforcement bar was connected to the concrete elements with joint elements incorporating the trilinear idealisation of the $\mathrm{MC} 90^{1}$ bond-slip relationship shown in Fig. 8 in which the slope of the unloading line was assumed to be parallel to the initial 


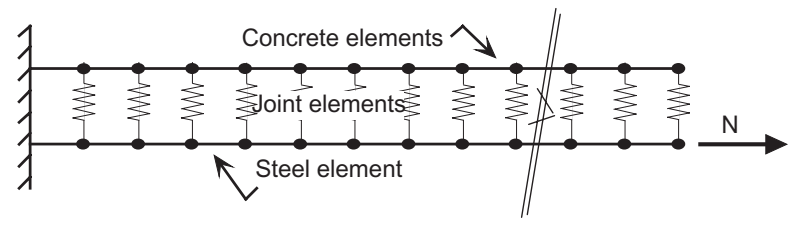

Fig. 7. Schematic of one-dimensional finite-element mesh used to model tension members

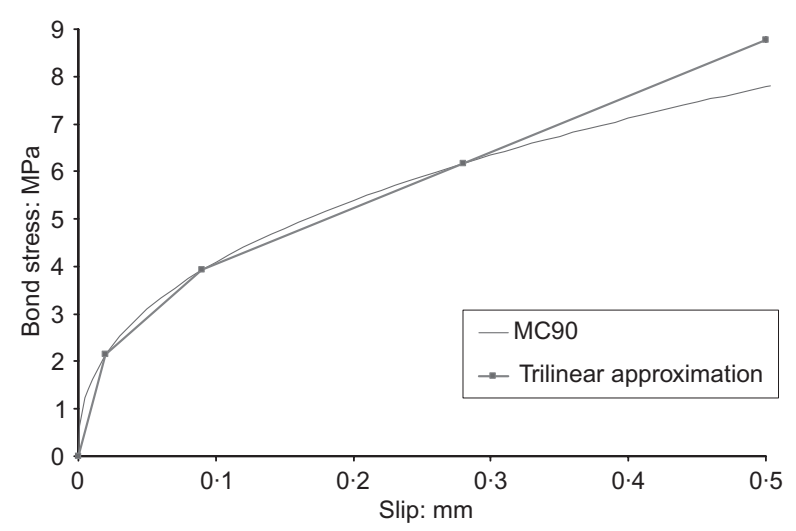

Fig. 8. Trilinear idealisation of MC90 bond-slip relationship

loading line. The concrete was modelled with a smeared crack model in which the tensile stress in the concrete was assumed to reduce linearly to zero after cracking. The crack strain at which the tensile stress reduced to zero was taken as

$$
\varepsilon_{\mathrm{u}}=2 G_{\mathrm{f}} / h f_{\mathrm{t}}
$$

where $G_{\mathrm{f}}$ is the fracture energy, $f_{\mathrm{t}}$ is the concrete tensile strength and $h$ is the length of each concrete element which was $10 \mathrm{~mm}$. The elements are considered to have been sufficiently short to simulate the formation of discrete cracks. The specimens were effectively oriented vertically in the analysis as in the tests and were loaded through the reinforcement at their upper end. Both the concrete and reinforcement were axially restrained at the lower end of the specimen, unlike the tests in which the load was applied through the reinforcement at each end of the member. The tensile strength of the concrete was assumed to be uniform throughout the member in the NLFEA. In reality, the concrete tensile strength varies stochastically along the member and cracks develop successively at the weakest sections. This behaviour was simulated in the NLFEA by applying a notional uniformly distributed vertical load to the concrete to introduce a stress gradient within the uncracked member. This reduced the tensile stress in the concrete at the base of the uncracked specimen by around $5 \%$ of the concrete tensile strength. The position of each crack was identified sequentially before it formed by identifying the element within which the stress in the concrete was greatest. The crack width was controlled at each crack sequentially, as it developed, with an arc length solution procedure. In this way, the width of the most recent crack was controlled throughout the analysis.

Table 1 summarises the concrete material properties used in the NLFEA analyses which were estimated from the loads at first cracking in the tension tests. There was some degree of subjectivity in determining the load at first cracking but this does not significantly influence the results. The difference between the tensile strengths given in Table 1 for the tension specimens at first cracking and the cylinder splitting tests is a measure of the tensile stress induced by restrained shrinkage prior to loading and the variability in strength between the control specimens and the ties.

\section{Results of analysis of Durham specimens}

Typical results are presented in this section from the analysis of the Durham ${ }^{2}$ specimens T12B1, T16B1, T16B2 and T20B1. The calculated load-displacement response is shown in Fig. 9 for specimen T12B1 which was typical. Snap-back occurred, with the member unloading almost elastically, after the formation of each crack since the elastic deformation recovery on unloading was greater than the increase in crack width owing to slip. The stiffness on reloading was governed by the number of cracks that had formed, which in turn governed the mean tensile stress in the concrete.

The change in stiffness on crack formation shown in Fig. 9 is similar to that shown by Beeby and $\mathrm{Scott}^{3}$ in their analysis of the tension specimen 100T12 tested by Scott and Gill. ${ }^{8}$ The essential difference is that Scott and Gill's ${ }^{8}$ tests were load controlled so that unloading

Table 1. Details of Durham ${ }^{2}$ tension specimens

\begin{tabular}{l|c|c|c|c}
\hline Specimen & $\begin{array}{c}\text { Bar dia: } \\
\text { mm }\end{array}$ & $\begin{array}{c}\text { Concrete cube } \\
\text { strengths*: MPa }\end{array}$ & $\begin{array}{c}\text { Concrete splitting } \\
\text { strength*: MPa }\end{array}$ & $\begin{array}{c}\text { Tensile strength used } \\
\text { in analysis: MPa }\end{array}$ \\
\hline T12B1 & 12 & 21.9 & 1.5 & 1.5 \\
T16B1 & 16 & 23.5 & 1.9 & 1.4 \\
T16B2 & 16 & 50.0 & 3.5 & 2.1 \\
T20B1 & 20 & 33.7 & 2.5 & 1.7 \\
\hline
\end{tabular}

* At start of test. 


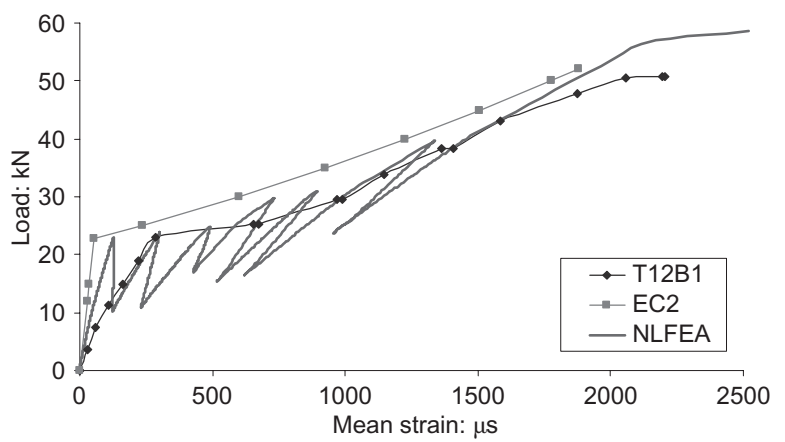

Fig. 9. Measured and predicted load plotted against mean strain in T12B1

did not occur after cracking. It is not therefore possible to assess the accuracy of the predicted unloading response from the essentially 'elastic' response of the specimen described by Beeby and Scott. ${ }^{3-4}$

\section{Comparison of measured and predicted crack development}

The loads at which cracks developed in the test specimens and the NLFEA are summarised in Table 2. Typically at least one more crack formed in the NLFEA than in the tests since the load was applied to the reinforcement at only one end in the NLFEA. The development of cracking in the NLFEA is discussed below for specimen T16B1, which was typical.

Cracks developed sequentially in the NLFEA of specimen T16B1 between $22 \mathrm{kN}$ and $96 \mathrm{kN}$ even though the concrete tensile strength was assumed to be essentially uniform throughout the member. An almost uniformly spaced crack pattern developed after the formation of the sixth crack at a load of $35 \mathrm{kN}$. The calculated crack spacing varied between 170 and $210 \mathrm{~mm}$ with a mean of $186 \mathrm{~mm}$, which is close to the measured mean spacing of $225 \mathrm{~mm}$ at $43.7 \mathrm{kN}$. Subsequently, two further cracks developed in the NLFEA at $96 \mathrm{kN}$. Figs 10(a) to (e) show the predicted distribution of stresses in the reinforcement, concrete and the corresponding bond stresses in specimen T16B1 just before the formation of the fourth crack at $27.5 \mathrm{kN}$ and at $73.3 \mathrm{kN}$ for direct comparison with the test data. The distribution of tensile stress in Fig. 10(a) is almost parabolic since the distribution of bond stress is almost linear as shown in Fig. 10(c). Following the formation of each crack, the peak value of the tensile stress increased up to the assumed concrete tensile strength when a further crack formed.

Table 2 shows that the NLFEA predicted the observed development of cracking well. Beeby ${ }^{3,9}$ has shown that an almost linear relationship exists between measured mean crack spacing and the reciprocal of the average strain at crack formation. The realism of the authors' NLFEA was therefore investigated further by plotting the mean crack spacing against 1/(average strain at crack formation). The mean crack spacing was calculated by dividing the specimen length by the number of cracks plus 1. Fig. 11 shows that the NLFEA predicted an almost linear relationship between the mean crack spacing and $1 /$ (average strain) for specimens T12B1, T16B1 and T20B1. The test values are not plotted in Fig. 11 since the strains at which cracks formed were not reported.

\section{Comparison of measured and predicted crack spacing}

The crack spacing is related to the distance $S_{0}$ over which the stress in the concrete increases from zero at a crack to the concrete tensile strength. It is readily shown that in the limit the crack spacing lies between $S_{0}$ and $2 S_{0}$ with an average spacing of around $1.5 S_{0}$ if it is assumed that no cracks can form within a distance $S_{0}$ of an existing crack. ${ }^{3}$ The distance $S_{0}$ is frequently assumed to be constant and related to the bar diameter and cover as in the Eurocode 2 (EC2) ${ }^{10}$ equation for the maximum crack spacing which is given below

$$
S_{\max }=2 S_{0}=3 \cdot 5 c+0.425 k_{1} k_{2} \phi / \rho
$$

Table 2. Development of cracking in Scott's test specimens

\begin{tabular}{|c|c|c|c|c|c|c|c|c|}
\hline \multirow[t]{4}{*}{ Specimen } & \multicolumn{4}{|c|}{ Test } & \multicolumn{4}{|c|}{ NLFEA } \\
\hline & \multirow{2}{*}{\multicolumn{2}{|c|}{$\begin{array}{c}\text { First load increment at } \\
\text { which strains were recorded } \\
\text { after cracking }\end{array}$}} & \multirow{2}{*}{\multicolumn{2}{|c|}{$\begin{array}{l}\text { Load at final crack during } \\
\text { initial loading }\end{array}$}} & \multicolumn{2}{|c|}{ First cracking } & \multicolumn{2}{|c|}{ Load* } \\
\hline & & & & & \multirow[t]{2}{*}{ Load: $\mathrm{kN}$} & \multirow{2}{*}{$\begin{array}{l}\text { Number of } \\
\text { cracks }\end{array}$} & \multirow[t]{2}{*}{ Load: kN } & \multirow{2}{*}{$\begin{array}{l}\text { Number of } \\
\text { cracks }\end{array}$} \\
\hline & Load: kN & $\begin{array}{l}\text { Number of } \\
\text { cracks }\end{array}$ & & cracks & & & & \\
\hline T12B1 & $25 \cdot 2$ & 2 & $29 \cdot 5$ & 3 & $23 \cdot 1$ & 1 & $29 \cdot 8$ & 5 \\
\hline T16B1 & $29 \cdot 0$ & 3 & $56 \cdot 9$ & 4 & $22 \cdot 9$ & 1 & $35 \cdot 1$ & 6 \\
\hline T16B2 & $32 \cdot 5$ & 1 & $53 \cdot 2$ & 4 & $32 \cdot 6$ & 1 & $46 \cdot 7$ & 6 \\
\hline $\mathrm{T} 20 \mathrm{~B} 1$ & $26 \cdot 5$ & 3 & $39 \cdot 3$ & 5 & $25 \cdot 1$ & 1 & $39 \cdot 5$ & 5 \\
\hline
\end{tabular}

* Closest load at crack formation to load at final crack in test. 


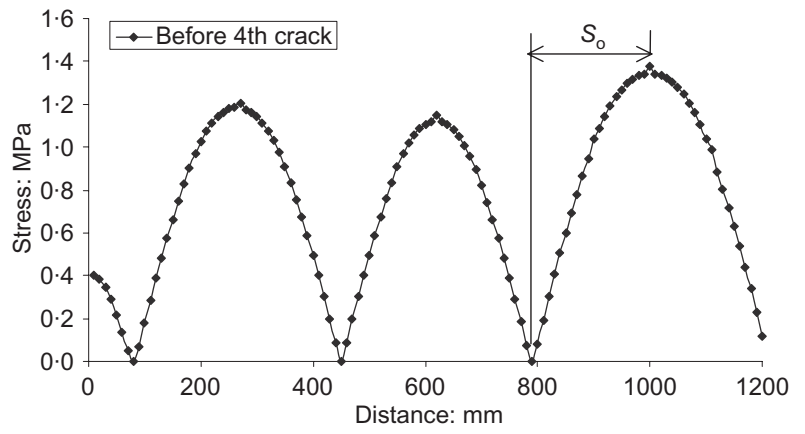

(a)

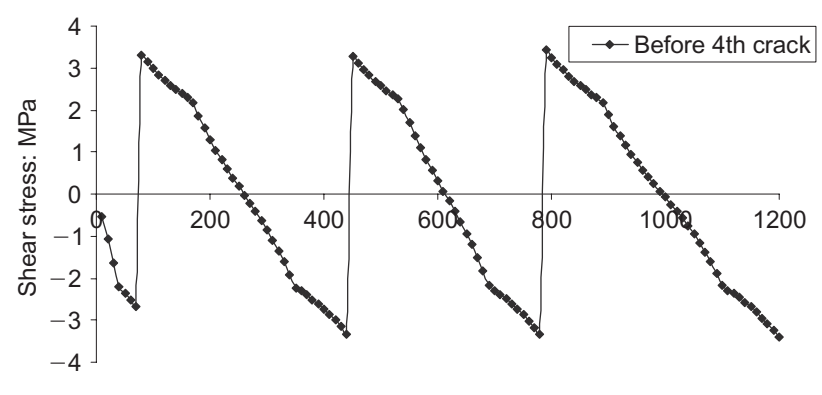

Distance: $\mathrm{mm}$

(c)

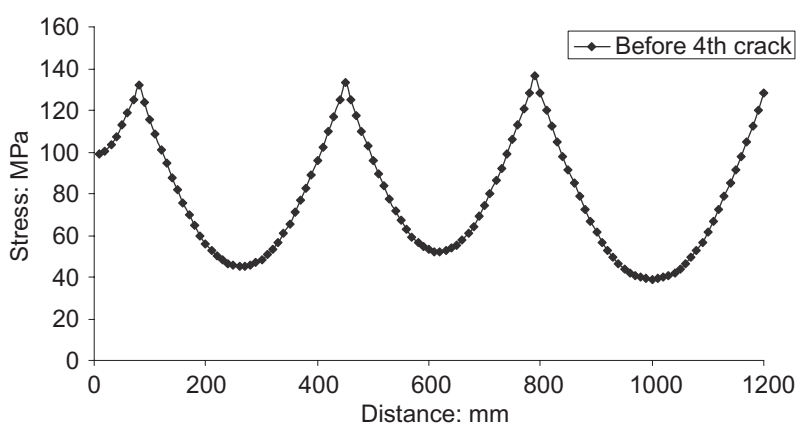

(b)

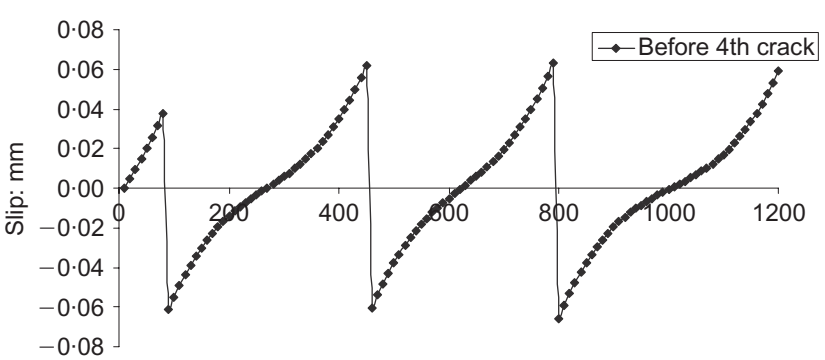

Distance: $\mathrm{mm}$

(d)

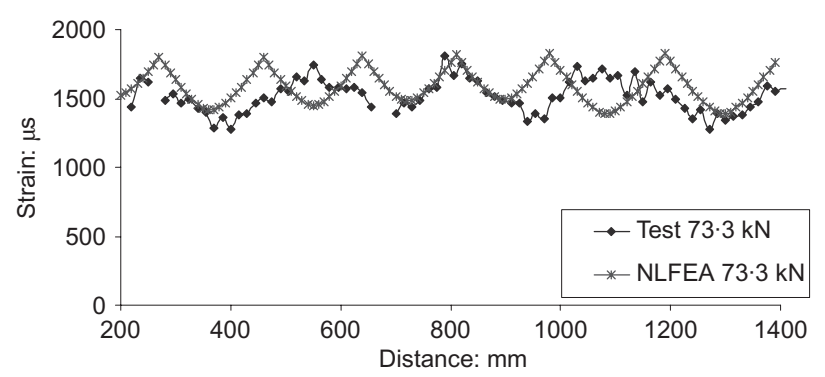

(e)

Fig. 10(a). Distribution of stress in concrete in T16B1 just before fourth crack forms at $27.5 \mathrm{kN}$; (b) distribution of stress in reinforcement in $T 16 B 1$ just before fourth crack forms at $27.5 \mathrm{kN}$; (c) distribution of bond stress in T16B1 just before fourth crack forms at $27.5 \mathrm{kN}$; (d) distribution of slip in T16B1 just before fourth crack forms at $27.5 \mathrm{kN}$; (e) comparison between measured and predicted reinforcement stress in $T 16 B 1$ at $73.3 \mathrm{kN}$

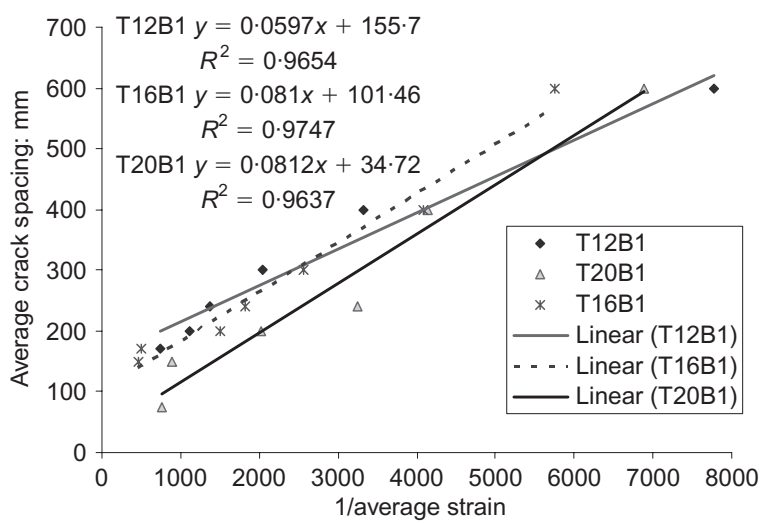

Fig. 11. Predicted relationship between 1/strain and crack spacing

where $c$ is the cover, $k_{1}=0 \cdot 8, k_{2}=1$ for pure tension, $\phi$ is the bar diameter and $\rho=A_{\mathrm{s}} / A_{\text {ceff }}$. Beeby ${ }^{11}$ showed that equation (3) can be derived by combining the nonslip and slip theories of cracking. The first term in 296 equation (3) is given by non-slip theory while the second term is given by slip theory which assumes plane sections remain plane and bond failure occurs. Neither of these assumptions is true but the latter is most significant since it implies that $S_{0}$ is constant, which is inconsistent with the predictions of bond-slip theory as discussed below.

The distance $S_{0}$, over which the concrete stress increased from zero at a crack to the concrete tensile strength, was extracted from the results of the current authors' NLFEA by examining the stress distribution in the concrete immediately before the formation of each crack (e.g. Fig. 10(a)). The results are plotted in Fig. 12 , which shows that the distance $S_{0}$ reduced significantly in the NLFEA as the crack pattern developed. This suggests that the crack spacing may not be uniquely defined in terms of the cover or ultimate bond strength as assumed in equation (3) since $S_{0}$ depends on the stress in the reinforcement at the crack which governs the slip and hence bond stress. It is also inter-

Magazine of Concrete Research, 2008, 60, No. 4 


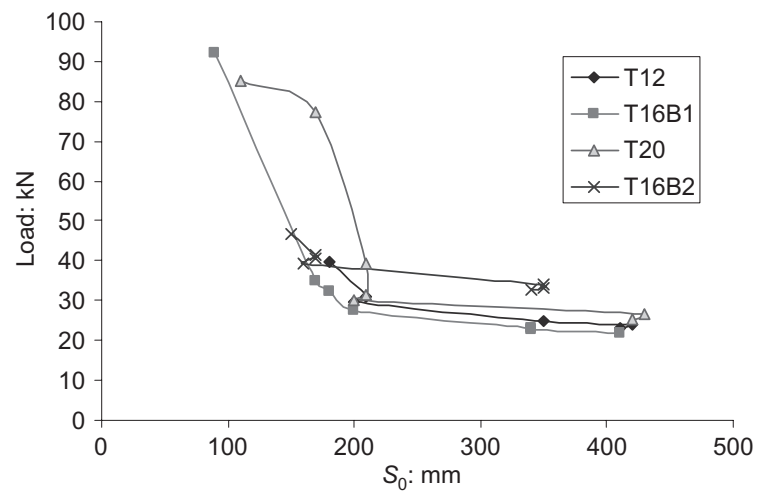

Fig. 12. Predicted load at cracking plotted against corresponding distance $S_{0}$

esting to note that cracking continued to develop until the reinforcement yielded in the NLFEA. This observation supports Beeby and Scott's ${ }^{4}$ hypothesis that the concept of a stabilised crack pattern is fictitious provided that the ultimate bond strength is not reached.

Mean crack spacings were calculated in the test specimens and NLFEA by dividing the distance between the points adjacent to each end of the specimen where the strain in the reinforcement was a minimum by the number of cracks. This procedure was adopted to minimise the influence of the different boundary conditions in the NLFEA and the test specimens. The resulting crack spacings are compared in Table 3 at the peak load applied in the tests for specimens T12B1, T16B1, T16B2 and T20B1 respectively. The mean crack spacings given by $\mathrm{EC} 2^{10}\left(0 \cdot 75 S_{\max }\right.$ from equation (3)) are also shown in Table 3 for comparison. Table 3 shows that the NLFEA gave reasonable estimates of the mean experimental crack spacing which was significantly overestimated by EC2. ${ }^{10}$

\section{Comparison between measured and predicted crack widths}

The crack width is given by the extension of the reinforcement relative to the concrete between adjacent points of zero slip to either side of the crack. The distance between the points of zero slip varies from $2 S_{0}$ after the formation of the first crack to a minimum of
$S_{0}$ as cracking develops. It follows that the maximum crack width is given by

$$
w_{\max }=2 S_{0}\left(\varepsilon_{\mathrm{sm}}-\varepsilon_{\mathrm{cm}}\right)
$$

where $\varepsilon_{\mathrm{sm}}$ is the mean strain in the reinforcement and $\varepsilon_{\mathrm{cm}}$ is the mean strain in the concrete. Beeby and $\mathrm{Scott}^{3}$ assumed that $S_{0}$ was $3.05 \mathrm{c}$ and that the bond stress was uniform but increased with load. In this case, they showed that assuming no interference between cracks, equation (4) can be simplified to

$$
w_{\max }=3.05 c \varepsilon_{\mathrm{s} 2}
$$

where $c$ is the cover and $\varepsilon_{\mathrm{s} 2}$ is the strain in the reinforcement at the crack.

$\mathrm{EC} 2{ }^{10}$ gives a formula for the maximum crack width which is equivalent to equation (6) below if $k_{\mathrm{t}}$ and $S_{\text {rmax }}$ are taken as 0.5 and $6 \cdot 10 c$ respectively

$$
w_{\max }=6 \cdot 10 c\left(\varepsilon_{\mathrm{s}}-0 \cdot 5 \varepsilon_{\mathrm{sr}}\right)
$$

where $\varepsilon_{\text {sr }}$ is the peak strain in the reinforcement at the end of the crack formation stage which is calculated in $\mathrm{EC} 2{ }^{10}$ using the mean tensile strength $f_{\mathrm{ctm}}$ at the time of cracking.

It is noteworthy that Beeby and $\mathrm{Scott}^{4}$ found that equation (5) gives good estimates of crack width in all cases in practice. The apparent universal applicability of equation (5) is inconsistent with the assumptions implicit in equation (6) for peak reinforcement strains greater than $\varepsilon_{\mathrm{sr}}$. Equation (6) is equivalent to equation (5) when the peak strain in the reinforcement is $\varepsilon_{\mathrm{sr}}$. It is assumed in the derivation of equation (6) that the tensile stress distribution in the concrete subsequently remains unchanged as the peak strain in the reinforcement increases from $\varepsilon_{\mathrm{sr}}$ to $\varepsilon_{\mathrm{s}}$. It follows that the maximum tensile stress in the concrete between cracks varies between $0 \cdot 5 f_{\mathrm{ct} i}$ for a crack spacing of $S_{0}$ to $f_{\mathrm{ct} i}$ for a crack spacing of $2 S_{0}$ where $f_{\text {ct } i}$ is the tensile strength at the formation of the $i$ th crack which EC2 ${ }^{10}$ takes as the mean tensile strength $f_{\text {ctm }}$ at the end of the crack formation phase.

Beeby and $\operatorname{Scott}^{3,4}$ justified the universal applicability of equation (5) by assuming that $(a)$ the distance $S_{0}$ over which the stress in the concrete increases from zero at a crack to $f_{\mathrm{ct} i}$ is constant and $(b)$ the bond stress is uniform but increases with applied load, allowing cracks to form within a distance $S_{0}$ of existing cracks.

Table 3. Comparison of measured and predicted crack spacing

\begin{tabular}{l|c|c|c|c|c}
\hline \multirow{2}{*}{ Specimen } & \multirow{2}{*}{ Load: $\mathrm{kN}$} & \multicolumn{4}{|c}{ Mean crack spacing: $\mathrm{mm}$} \\
\cline { 3 - 6 } & & Test & EC2 & NLFEA & $4 \cdot 6 c$ \\
\hline T12B1 & $50 \cdot 8$ & 300 & 528 & 200 & 247 \\
T16B1 & $73 \cdot 0$ & 225 & 425 & 186 & 238 \\
T16B2 & $72 \cdot 0$ & 225 & 425 & 176 & 238 \\
T20B1 & $72 \cdot 0$ & 200 & 360 & 196 & 229 \\
\hline
\end{tabular}


They further allowed the concrete tensile stress at cracking $f_{\mathrm{ct} i}$ to increase up to a maximum of three times the stress at first cracking. The main consequence of these assumptions is that the mean crack spacing is not limited to $1 \cdot 5 S_{0}$ as frequently assumed since cracks can form within a distance $S_{0}$ of existing cracks.

Beeby and Scott's ${ }^{3,4}$ description of cracking has many similarities with the predictions of the current authors' NLFEA as discussed in this paper. The most fundamental differences are as follows

(a) Beeby and $\mathrm{Scott}^{3,4}$ assume $S_{0}$ to be constant whereas the current authors' NLFEA predicts $S_{0}$ to reduce with load, as shown in Fig. 12.

(b) Beeby and $\mathrm{Scott}^{3,4}$ assume the bond stress is uniform over $S_{0}$ and that it increases in proportion to the applied load until it reaches a limiting value. The authors' analysis of the Durham ${ }^{2}$ strain data suggests that the bond stress increased with slip much as predicted by the MC90 bond-slip relationship as shown in Figs 3 to 6

(c) Beeby and $\mathrm{Scott}^{3,4}$ assume that the concrete tensile strength varies by a factor of 3 within the member whereas the authors assumed it to be essentially uniform.

Crack widths are not reported for the Durham tests ${ }^{2}$ but have been estimated by dividing the extension of the specimen by the number of cracks. This procedure neglects the reduction in crack width owing to the extension of the concrete but analysis of the strain distribution in the reinforcement suggests that the error is likely to be less than $0.02 \mathrm{~mm}$. The extension of the Durham $^{2}$ specimens was calculated from axial strains measured with a Demec gauge on consecutive $200 \mathrm{~mm}$ gauge lengths over opposite sides of each specimen. The strains were typically greater on one side of the specimen than the other, indicating the presence of curvature owing to the non-symmetric development of cracking. The effect of curvature was eliminated in the calculation of crack width by averaging the strains on opposite faces of the specimens. The resulting mean strains compared well with the mean strains measured in the reinforcement, which indicates that plane sections remained plane over the Demec gauge length.

Crack widths were calculated $(a)$ from the sum of the slips to either side of each crack in the NLFEA, $(b)$ with EC2, (c) with equation (5) (which Beeby and $\mathrm{Scott}^{4}$ found to give good estimates of crack width) and (d) with equation (6). Mean crack widths were calculated with EC2 and equation (6) assuming the mean crack spacing was $\frac{3}{4}$ the maximum spacing. The maximum crack widths from the NLFEA are shown to compare very well with the crack widths given by equation (5) in Fig. 13 in which the crack width is plotted against the strain in the reinforcement at the cracks. The experimental and predicted mean crack widths are compared in Fig. 14 which shows that mean crack widths were slightly underestimated by both the

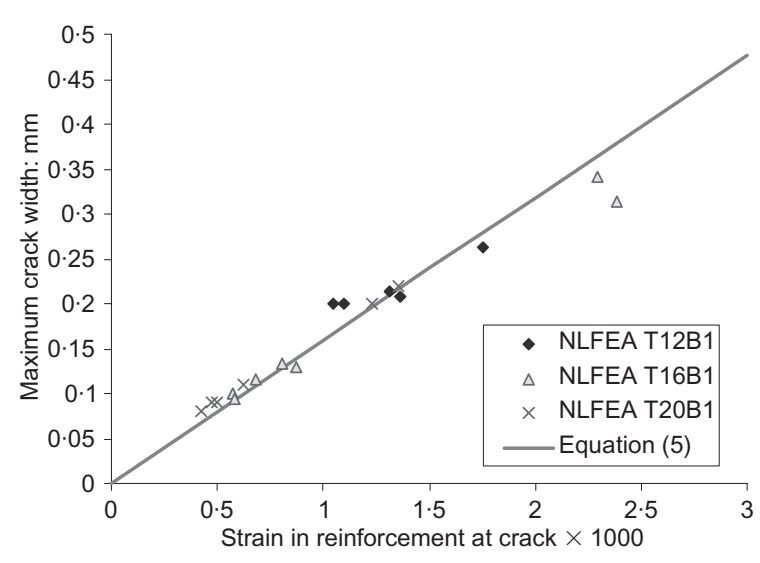

Fig. 13. Comparison of predicted maximum crack widths

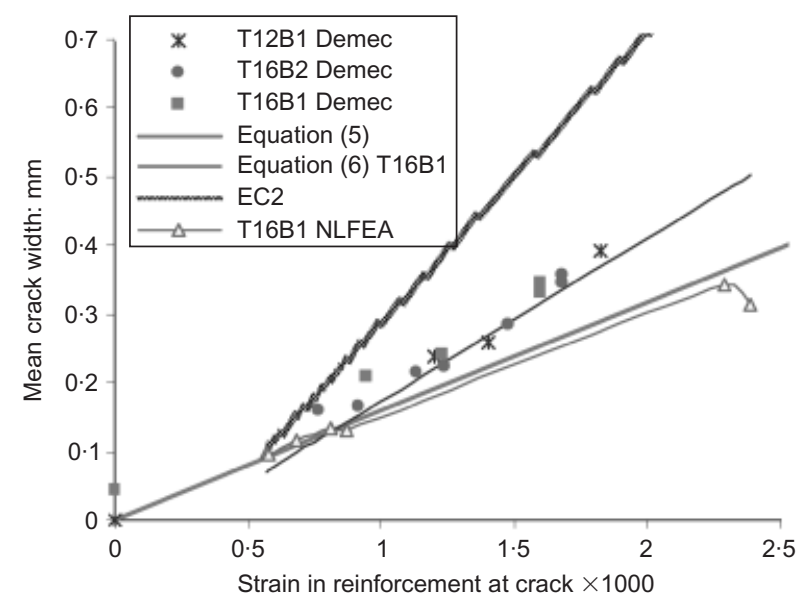

Fig. 14. Comparison of measured and predicted mean crack widths

NLFEA and equation (5). Equation (6) which is equivalent to the crack width equation in $\mathrm{EC} 2^{10}$ but with a reduced mean crack spacing of $0.75 \times 6 \cdot 1 c=4.6 c$ gives the best results which is unsurprising since the crack spacing of $4 \cdot 6 c$ is close to the experimental values (see Table 3). As a final point, it is interesting to note that the NLFEA predicts a linear relationship between peak reinforcement strain and crack width as found by Beeby and $\mathrm{Scott}^{4}$ in their analysis of Farra and Jaccoud's tension specimens. ${ }^{12}$

\section{Tension stiffening}

The mean strain in the reinforcement is governed by the residual tensile stress in the concrete after cracking. It is important to recognise that the crack width depends on the tensile stress distribution in the concrete to either side of the crack between the points of zero slip. On the other hand, the extension of a reinforced concrete tie is related to the mean tensile stress in the concrete $f_{\text {tm }}$ along the complete member which in turn is related to the number of cracks. It follows that differ- 
ent expressions should be used for the calculation of the mean strain in the reinforcement in crack width and displacement calculations, as is done in EC2, unless individual cracks are modelled in the displacement calculation as done by Beeby and $\mathrm{Scott}^{3}{ }^{3}$ The mean concrete tensile stress $f_{\mathrm{tm}}$ in a complete tension member is given by

$$
f_{\mathrm{tm}}=\left(N-A_{\mathrm{s}} E_{\mathrm{s}} \varepsilon_{\mathrm{sm}}\right) / \mathrm{A}_{\mathrm{c}}
$$

where $\varepsilon_{\mathrm{sm}}$ is the mean strain averaged along the complete length of the member, $A_{\mathrm{S}}$ is the area of reinforcement and $A_{\mathrm{c}}$ the area of concrete.

Equation (7) was used to calculate the mean tensile stress in the concrete in the Durham specimens ${ }^{2}$ from the mean strains measured in the tests. The mean tensile stress was also calculated in the NLFEA just before the formation of each crack. The resulting tensile stresses are plotted in Figs 15(a) to (d), which show that the current authors' NLFEA gives good estimates of the residual tensile stress measured in the concrete.

In EC2, ${ }^{10}$ the mean instantaneous axial strain is found as follows by interpolating between the strains in uncracked $\varepsilon_{1}$ and fully cracked sections $\varepsilon_{2}$

$$
\varepsilon_{\mathrm{m}}=(1-\zeta) \varepsilon_{1}+\zeta \varepsilon_{2}
$$

where

$$
\zeta=1-\beta\left(N_{\mathrm{r}} / N\right)^{2}
$$

$N_{\mathrm{r}}$ is the load at first cracking and $\beta$ is a coefficient that is taken as 1 for short-term loading

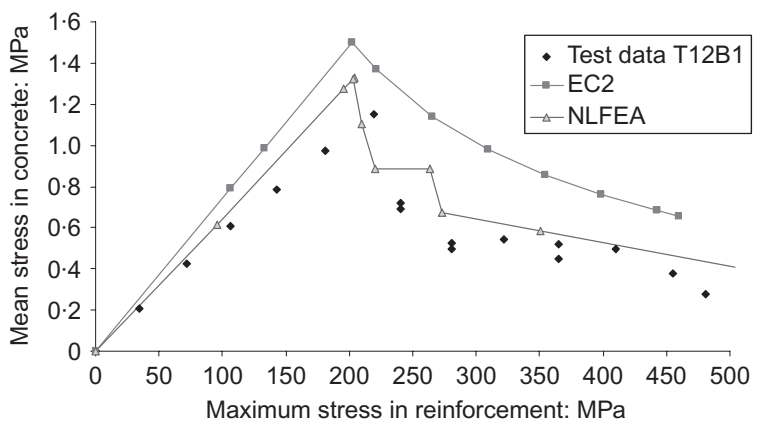

(a)

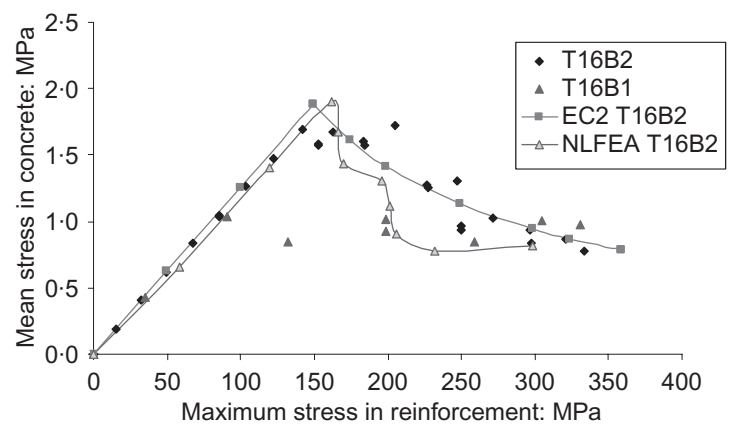

(c)

$$
\begin{gathered}
\varepsilon_{1}=N /\left[E_{\mathrm{c}} A_{\mathrm{c}}(1-m \rho)\right] \\
\varepsilon_{2}=N /\left[A_{\mathrm{s}} E_{\mathrm{s}}\right] \\
m=E_{\mathrm{s}} / E_{\mathrm{c}} \\
\rho=A_{\mathrm{s}} / A_{\mathrm{c}}
\end{gathered}
$$

Figure 9, which was typical, shows that both the NLFEA and $E C 2^{10}$ gave reasonable estimates of the measured mean axial strain in T12B1. The EC2 ${ }^{10}$ analysis underestimated the axial strains before cracking since it did not account for the fact that the members were loaded through the reinforcement at each end. Similarly, the NLFEA underestimated the initial strain before cracking since the specimen was only loaded through the reinforcement at one end. Overall it is concluded that both the NLFEA and equation (9) realistically account for the progressive loss of tension stiffening owing to successive crack formation. According to $\mathrm{EC} 2{ }^{10}$ the mean concrete tensile stress in the tension member $f_{\mathrm{tm}}$ is given by

$$
f_{\mathrm{tm}}=(1-\zeta) N /\left[A_{\mathrm{c}}(1+m \rho)\right]
$$

Equation (14) was used to calculate the mean stress in the Durham ${ }^{2}$ tension specimens with $\beta=1$ for instantaneous loading. The results are plotted in Figs 15(a) to (d), which show that EC2 ${ }^{10}$ tended to overestimate the mean residual tensile stress in the concrete. This observation is consistent with Fig. 9 which shows that EC2 slightly underestimated the axial strain in T12B1.

The loss of tension stiffening in the test specimens (see Figs 15(a) to (d)) can be related to the develop-

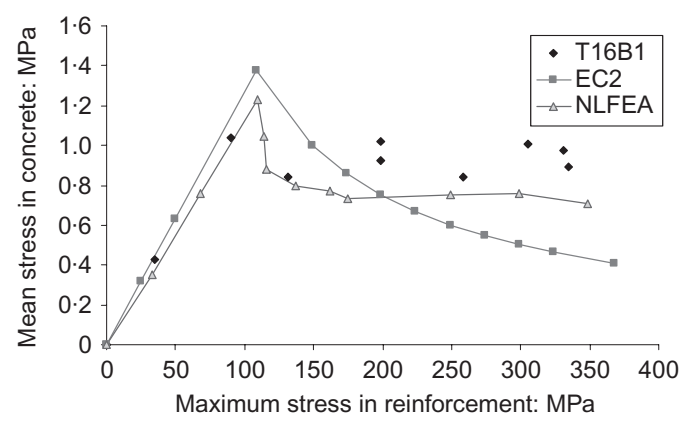

(b)

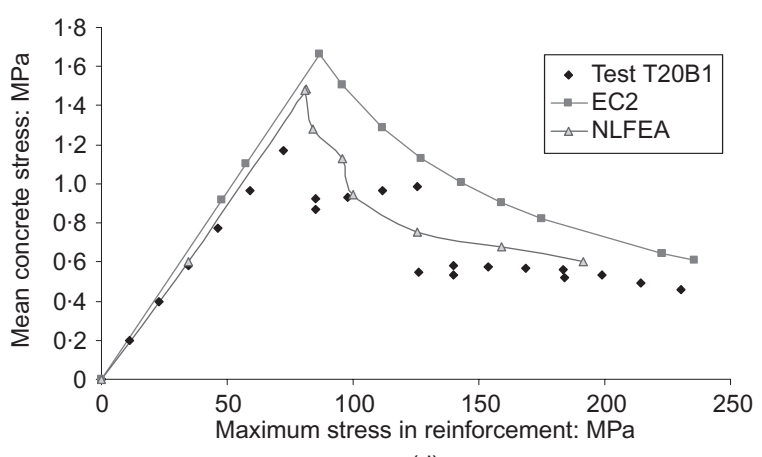

(d)

Fig. 15. Comparison between measured and predicted tension stiffening in (a) T12B1; (b) T16B1; (c) T16B2; (d) T20B1 
ment of cracking. For example, Fig. 15(c) shows that the mean tensile stress in the concrete remained almost constant in T16B1 after cracking, unlike T16B2 where it reduced progressively. Analysis of the experimental data shows that three cracks had formed in T16B1 at a load of $29 \mathrm{kN}$, whereas four cracks formed progressively in T16B2 between $32.5 \mathrm{kN}$ and $53.2 \mathrm{kN}$. Similarly, the steep loss in tension stiffening in T20B1 (see Fig. 15(d)) at a reinforcement stress of $125 \mathrm{MPa}$ (corresponding to a slip of $0.07 \mathrm{~mm}$ in Fig. 6) occurred owing to the formation of two additional primary cracks. The mean tensile stress in the concrete remained fairly constant thereafter up to the maximum load of $73 \mathrm{kN}$. This is reflected in Fig. 6, which shows that the mean bond stress only increased marginally as the slip increased above $0.7 \mathrm{~mm}$. Beeby and $\operatorname{Scott}^{2,3}$ suggested that the tension stiffening effect in the Durham $^{2}$ tests was independent of the concrete tensile strength. The present authors suggest that this is only the case after the onset of multiple cracking, which is dependent on the concrete tensile strength. The current authors' NLFEA appears to predict the influence of concrete tensile strength on tension stiffening more realistically than EC2, ${ }^{10}$ which appears to overestimate its influence.

\section{Conclusion}

It has been shown that the development of cracking in axially reinforced tension members can be predicted well with a simple one-dimensional finite-element model in which bond-slip is modelled with the MC90 ${ }^{1}$ bond-slip relationship. Contrary to the conclusions of Beeby and Scott, ${ }^{2-4}$ who argued that bond stress is constant between cracks under a given load, it is suggested that the Durham ${ }^{2}$ reinforcement strain data are broadly consistent with the predictions of the MC90 bond-slip model in a one-dimensional analysis. The NLFEA confirms Beeby and Scott's ${ }^{2-4}$ view that there is no theoretical reason for a unique relationship between crack spacing, bar diameter and ultimate bond strength as commonly assumed. Rather, it is shown that the distance $S_{0}$ over which the stress in the concrete increases from zero at a crack to the tensile strength of concrete reduces with increasing load owing to the increase in bond stress with slip. The NLFEA predicted the crack spacing reasonably even though the effect of cover was not modelled explicitly. This appears to be the case since the cross-sectional area of the section, and hence the cracking load, is approximately proportional to the cover. ${ }^{2}$ It is concluded that the MC90 bond-slip relationship can be used to relate bond stress to the relative displacements between the concrete, surrounding the internal cracking zone, and steel.

\section{References}

1. Comité Euro-International du Béton. CEB-FIP Model Code for Concrete Structures. Thomas Telford, London, 1990, MC90.

2. Beeby A. W. and Scott R. H. Tension Stiffening of Concrete, Behaviour of Tension Zones in Reinforced Concrete including Time Dependent Effects. Supplementary Information, The Concrete Society, Camberley, 2004, Technical Report 59.

3. Beeby A. W. and Scott R. H. Insights into the cracking and tension stiffening behaviour of reinforced concrete tension members revealed by computer modelling. Magazine of Concrete Research, 2004, 56, No. 3, 179-190.

4. Beeby A. W. and Scott R. H. Cracking and deformation of axially reinforced concrete members subjected to pure tension. Magazine of Concrete Research, 2005, 57, No. 10, 611-621.

5. Gото Y. Cracks formed in concrete around deformed tension bars. Journal of the American Concrete Institute, 1971, 68, No. 4, 244-251.

6. Balzas G. L. Structural Concrete Textbook on Behaviour, Design and Performance, Vol. 2: Basis Design Manual-Textbook. International Federation for Structural Concrete (fib), Lausanne, Switzerland, 1999.

7. Izzuddin B. A. Nonlinear Dynamic Analysis of Framed Structures. PhD thesis, Department of Civil Engineering, Imperial College, University of London, 1991.

8. Scott R. H. and Gill P. A. T. Short term distributions of strain and bond stress along tension reinforcement. The Structural Engineer, 1987, 65B, No. 2, 39-43.

9. Beeby A. W. A Study of Cracking in Reinforced Concrete Members Subject to Pure Tension. Cement and Concrete Association, London, 1972, Report 42.468.

10. British Standards Institution. Eurocode 2, Design of Concrete Structures. Part 1: General Rules for Buildings. BSI, London, 2004.

11. BEEBY A. W. The prediction of crack widths in hardened concrete. The Structural Engineer, 1979, V57A, No. 1, 9-17.

12. FARRA B. and JACCOUd J.-P. Influence du Béton et de L'armature sur la Fissuration des Structures en Béton. Rapport des Essais de Tirants sous déformation Imposé de Court Durée. Départment de Génie Civil, Ecole Polytechnique Fédérale de Lausanne, November 1993, Publication No. 140.

Discussion contributions on this paper should reach the editor by 1 November 2008 